\title{
Transcriptional profile of oil palm pathogen, Ganoderma boninense, reveals activation of lignin degradation machinery and possible evasion of host immune response
}

\author{
Braham Dhillon ${ }^{1 *} \mathbb{D}$, Richard C. Hamelin ${ }^{2}$ and Jeffrey A. Rollins ${ }^{3}$
}

\begin{abstract}
Background: The white-rot fungi in the genus Ganoderma interact with both living and dead angiosperm tree hosts. Two Ganoderma species, a North American taxon, G. zonatum and an Asian taxon, G. boninense, have primarily been found associated with live palm hosts. During the host plant colonization process, a massive transcriptional reorganization helps the fungus evade the host immune response and utilize plant cell wall polysaccharides.
\end{abstract}

Results: A publicly available transcriptome of $G$. boninense - oil palm interaction was surveyed to profile transcripts that were differentially expressed in planta. Ten percent of the G. boninense transcript loci had altered expression as it colonized oil palm plants one-month post inoculation. Carbohydrate active enzymes (CAZymes), particularly those with a role in lignin degradation, and auxiliary enzymes that facilitate lignin modification, like cytochrome P450s and haloacid dehalogenases, were up-regulated in planta. Several lineage specific proteins and secreted proteins that lack known functional domains were also up-regulated in planta, but their role in the interaction could not be established. A slowdown in G. boninense respiration during the interaction can be inferred from the downregulation of proteins involved in electron transport chain and mitochondrial biogenesis. Additionally, pathogenicity related genes and chitin degradation machinery were down-regulated during the interaction indicating $G$. boninense may be evading detection by the host immune system.

Conclusions: This analysis offers an overview of the dynamic processes at play in G. boninense - oil palm interaction and provides a framework to investigate biology of Ganoderma fungi across plantations and landscape.

Keywords: Ganoderma, Boninense, Plant-pathogen interaction, Differentially expressed genes, White-rot, Oil palm, RNA-seq, Transcriptome

\footnotetext{
* Correspondence: dhillonb@ufl.edu

'Department of Plant Pathology, University of Florida, Fort Lauderdale Research and Education Center, Davie, FL 33314, USA

Full list of author information is available at the end of the article
}

C C The Author(s). 2021 Open Access This article is licensed under a Creative Commons Attribution 4.0 International License, which permits use, sharing, adaptation, distribution and reproduction in any medium or format, as long as you give appropriate credit to the original author(s) and the source, provide a link to the Creative Commons licence, and indicate if changes were made. The images or other third party material in this article are included in the article's Creative Commons licence, unless indicated otherwise in a credit line to the material. If material is not included in the article's Creative Commons licence and your intended use is not permitted by statutory regulation or exceeds the permitted use, you will need to obtain permission directly from the copyright holder. To view a copy of this licence, visit http://creativecommons.org/licenses/by/4.0/. The Creative Commons Public Domain Dedication waiver (http://creativecommons.org/publicdomain/zero/1.0/) applies to the data made available in this article, unless otherwise stated in a credit line to the data. 


\section{Background}

The Ganoderma genus in the order Polyporales contains laccate (shiny) shelf fungi found in temperate and tropical forests and urban landscapes. Ganoderma is a diverse genus of wood decay fungi, with both opportunist species that grow on decaying or dead wood, and pathogenic species that attack and kill trees. Wooddecay fungi exist across a degradation continuum depending on the plant cell wall components they decompose [1]. Brown-rot fungi breakdown cellulose but cannot metabolize lignin, whereas, white-rot fungi, like, Ganoderma, carry the necessary enzymes needed to mineralize lignin, in addition to enzymes that degrade cellulose and hemicellulose [2].

As with other macrofungi, species of Ganoderma were traditionally described based on their macromorphology, host and geography [3-5]. In North America, 13 species of Ganoderma were resolved molecularly [6], with additional species recognized in Europe and Asia [7]. Multilocus phylogeny clustered Ganoderma taxa into three clades that were not constrained by geographical origin $[6,7]$. Clade $C$ contains two species, G. zonatum, native to North America and its sister species from Asia, G. boninense. Both species are found in sub-tropical and tropical regions and have been collected from the monocot plant host, palms, family Arecaceae.

Palms are 'the' iconic plant species of the tropics. There are $\sim 2600$ species of palms that dot the landscape in tropical and sub-tropical ecosystems. Palms are an important part of the social and economic spheres, both globally and locally. Even though palms are well-known for three edible products i.e. coconuts, dates and oil, they are a source for other commodities like palm syrup, nuts, jams/jellies, wine, dyes, carnauba wax, rattan cane and wood. In 2018, palm oil accounted for $40.2 \%$ of the world's vegetable oil production, with $85 \%$ of the total palm oil being produced in Malaysia and Indonesia [8]. In 2016, an industry based on one commodity, palm oil, generated 2.9 million jobs world-wide and contributed $\$ 39$ billion to the global GDP [9].

G. boninense, a soil-borne fungus that colonizes its host through the roots [10], poses a serious threat to oil palm plantations in southeast Asia [11]. Similarly, G. zonatum has been described as a pathogen on palms in the southeastern US [12]. Both Ganoderma species associate with palms and may share mechanisms that facilitate palm tissue colonization. Genomic and transcriptomic analyses and comparisons can help us understand these mechanisms and develop better control methods. To understand the gene expression changes that occur in the white-rot fungus $G$. boninense as it interacts with its oil palm host, Elaeis guineensis, a publicly available RNAseq dataset was obtained from GenBank and analyzed. The objective was to identify the genes that are differentially expressed during the interaction and allow G. boninense to colonize and cause disease in its palm host. Insights into the mechanics of Ganoderma-palm interaction gained from G. boninense pathosystem will inform and address questions related to the biology and disease ecology of G. zonatum.

\section{Results}

The Ganoderma boninense genome [13] and G. boninense - Elaeis guineensis interaction transcriptome [14], were obtained from NCBI and analyzed. An average of 156 and 131 million RNAseq reads were generated from three biological replicates for the two growth conditions: (1) in vitro, i.e., G. boninense grown on artificial media, and (2) in planta, i.e., G. boninense interacting with roots of oil palm seedlings, respectively. The reads from the in vitro $(82 \%)$ and in planta (57\%) growth conditions that mapped to the $G$. boninense genome (Table 1) were assembled to generate a dataset of 15,536 loci. A total of 1560 differentially expressed genes (DEGs; absolute value $\left.\left[\log _{2} \mathrm{FC}>2\right] ; \mathrm{p}_{\mathrm{adj}}<0.05\right)$ were identified with 669 and 891 transcripts that were up- and down-regulated, respectively, in planta when compared to the artificial media (Additional file 1: Table S1). Principal component analysis using the transformed normalized counts showed that the first component explained $89 \%$ of the variation and clearly separates the transcriptome samples derived from in vitro and in planta growth conditions (Fig. 1). The three replicates within the in planta group had low variation, with some separation of the G. boninense transcriptome obtained from samples grown in vitro along the second principal component (Fig. 1).

The assembled loci and derived proteins were annotated by comparing the sequences with different databases (Fig. 2). A search against the Pfam and NCBI Conserved Domain Database (CDD) databases using the Reverse Position-Specific BLAST (RPS-BLAST) [15], also known as CD-search (Conserved Domain Search), identified protein domains in 59.4\% (9228) of the assembled transcript loci (Fig. 2a). Although Pfam models

Table 1 Mapping statistics of the reads aligned to the Ganoderma boninense genome

\begin{tabular}{llll}
\hline & Reads (Total) & Reads (Mapped) & Percent mapped \\
\hline In vitro (Rep1) & $136,217,626$ & $113,700,928$ & 83.5 \\
In vitro (Rep2) & $167,719,900$ & $141,320,277$ & 84.3 \\
In vitro (Rep3) & $165,359,157$ & $133,937,580$ & 81.0 \\
In vitro (Avg) & $\mathbf{1 5 6 , 4 3 2 , 2 2 8}$ & $\mathbf{1 2 9 , 6 5 2 , 9 2 8}$ & $\mathbf{8 2 . 9}$ \\
In planta (Rep1) & $163,887,796$ & $88,314,747$ & 53.9 \\
In planta (Rep2) & $83,977,832$ & $44,634,655$ & 53.2 \\
In planta (Rep3) & $146,185,776$ & $95,274,605$ & 65.2 \\
In planta (Avg) & $\mathbf{1 3 1 , 3 5 0 , 4 6 8}$ & $\mathbf{7 6 , 0 7 4 , 6 6 9}$ & $\mathbf{5 7 . 4}$ \\
\hline
\end{tabular}




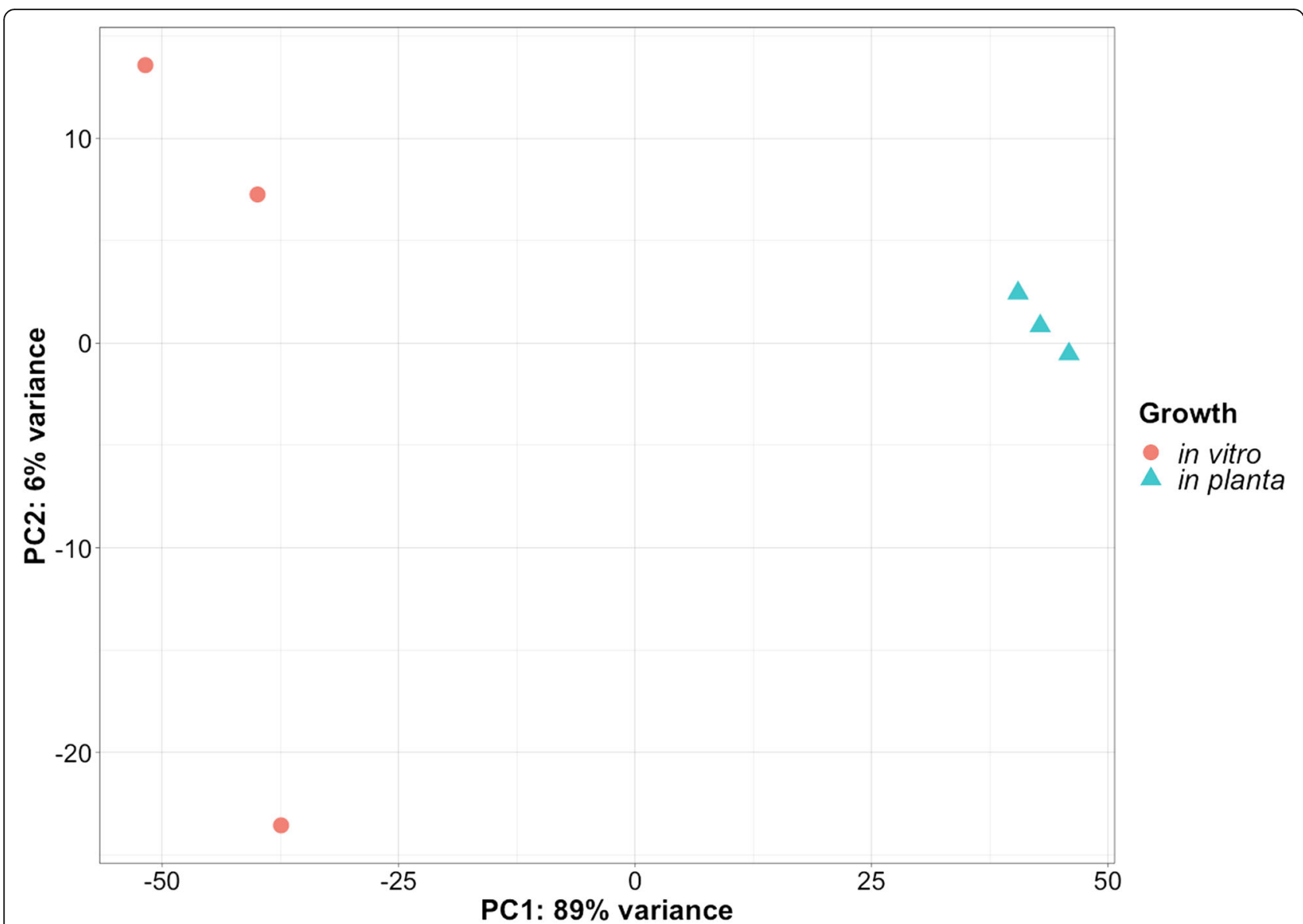

Fig. 1 Principal component analysis of six Ganoderma boninense samples used for RNAseq. Principal component analysis (PCA) was conducted using transformed normalized read counts for 15,536 transcript loci. The three replicates for each group, fungal growth in vitro and in planta, are color coded red and green, respectively

contribute to the NCBI-CDD, the use of Pfam database provided annotation for an additional $\sim 1.5 \%$ of the total as well as differentially expressed transcripts (Fig. 2a, b). Secreted proteins $(402,4.5 \%)$ and CAZymes $(253,2.8 \%)$ were identified from predicted protein coding regions (8899) extracted from the RNAseq transcript loci with domain annotations being available for $58.8 \%$ of the secreted proteins and 90.1\% CAZymes (Fig. 2a). Approximately $72 \%$ (1119) of the transcript loci that comprise the in planta DEGs dataset had an annotation and $55.2 \%$ of the secreted DEGs and $90.8 \%$ of the CAZyme DEGs contained annotated protein domains (Fig. 2b).

\section{CAZymes and other genes involved in lignocellulosic degradation}

Various classes of carbohydrate active enzymes (CAZymes) were differentially regulated during the $G$. boninense - oil palm interaction compared to in vitro growth on artificial medium (Fig. 3). The auxiliary activities (AA) family of CAZymes that are present in whiterot fungi showed increased expression as the fungus $G$. boninense was colonizing the root tissue of its oil palm host. CAZymes belonging to six families of AA enzymes that specialize in utilizing lignocellulosic substrates and associated byproducts were up-regulated: five multicopper oxidases (AA1_1), four glucose-methanol-choline (GMC) oxidoreductases (AA3), one each of peroxidase (AA2), copper radical oxidase (AA5), and benzoquinone reductase (AA6). Additionally, an enzyme with copperdependent lytic polysaccharide monooxygenase (LPMO) activity that belongs to the AA9 (formerly GH61) family also showed higher expression in $G$. boninense during its interaction with the plant host.

CAZymes may contain additional non-catalytic modules, carbohydrate binding modules (CBMs), that aid in binding to carbohydrates. At least two enzymes that contain the fungal specific cellulose binding CBM1 domain and one enzyme with galactose binding CBM51 domain were up-regulated as $G$. boninense was utilizing carbon from its oil palm host.

Another family of CAZymes called glycoside hydrolases (GH) target the cellulosic, hemicellulosic, and pectic 

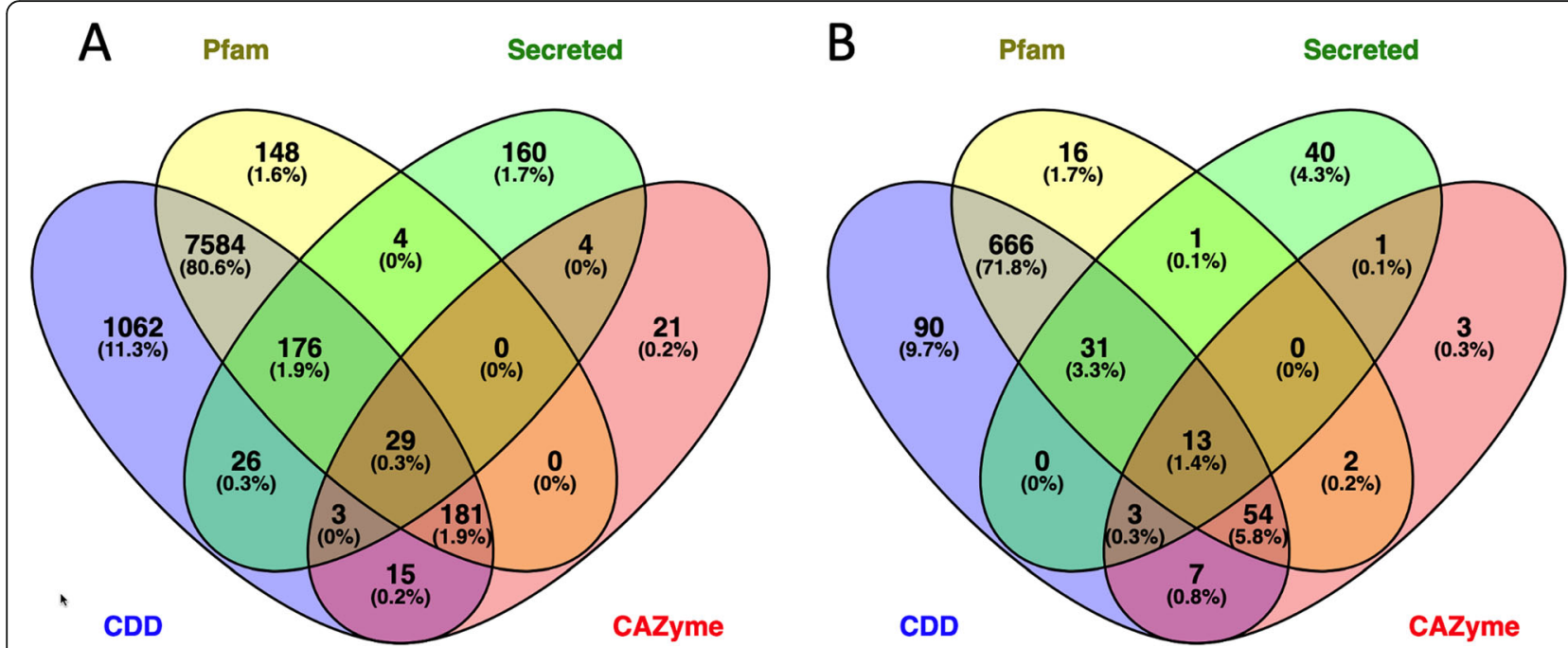

Fig. 2 Number of transcripts and differentially expressed genes that were annotated. Venn diagram shows the overlap between database sources for annotated a transcript loci and $\mathbf{b}$ differentially expressed genes. CDD - Conserved Domain Database (NCBI), Pfam - Protein family database, Secreted - proteins with secretion signal, CAZyme - Carbohydrate Active enZymes

compounds in plant cell walls. In the interaction between G. boninense and its host, enzymes involved in hemicellulose breakdown were up-regulated, including two xyloglucan hydrolases (GH16 or endo-1,3(4)- $\beta$-glucanase EC 3.2.1.6) that target cereal $\mathrm{D}$-glucans, one $\alpha$-glucosidase (GH31), two $\beta$-galactosidases (GH35, GH35-CBM51), one GH1, six GH3 including two GH3s that are secreted and two $\alpha$-glucuronidases (GH115, secreted GH115-CE15) that remove glucuronic acid residues from xylans were up-regulated. CAZymes in the GH family that target pectins (including two GH28, one GH43, one GH51, one CE12), and two $\beta$-glucuronidases (GH79) were also upregulated. Additionally, four $\alpha$-mannosidases (one each belonging to $\mathrm{GH}$ families $\mathrm{GH} 38, \mathrm{GH} 47, \mathrm{GH} 92$, and GH125) showed elevated expression in G. boninense during its interaction with oil palm root tissue.

Two pectate lyases (PL3), one secreted PL8 protein and one alginate lyase domain containing protein from the CAZyme polysaccharide lyase (PL) family of enzymes were also up-regulated during the interaction.

\section{Oxalic acid biosynthesis and degradation}

In the G. boninense transcriptome, two copies of oxalate decarboxylases (ODCs) were significantly up-regulated in planta. In fact, these two ODCs were among the top 20 most up-regulated DEGs. A third copy of ODC was up-regulated while $G$. boninense was growing on the artificial medium. Two putative copies of oxaloacetate acetylhydrolase, a gene responsible for oxalate biosynthesis, were identified in the G. boninense genome but were not differentially expressed during the interaction. Four copies of formate dehydrogenases (FDHs) that degrade formate were differentially expressed. One FDH copy was up-regulated as G. boninense was interacting with the oil palm host, whereas three copies were upregulated during growth on the artificial medium.

\section{Microbe-associated molecular patterns (MAMPs)}

Chitin, a major component of fungal cell walls, also acts as a potent microbe-associated molecular pattern (MAMP) that can be recognized by the plant immune system. A chitin synthase (CHS), chitinase and endochitinase were up-regulated during the G. boninense - oil palm interaction. Fungal genes involved in chitin breakdown, including five chitinases, two beta-glucanases and one beta-acetyl hexosaminidase [16], were downregulated during the interaction. Another modular chitinase that contained a PX domain was also up-regulated during the interaction. A PX domain carrying chitinase protein described earlier in Phanerochaete chrysosporium was shown to be expressed but chitinolytically inactive [17]. Furthermore, four G. boninense proteins with a CBM50 domain, also known as chitin binding LysM domain, were down-regulated during this interaction.

Additionally, the expression of pathogenicity related genes known from other pathosystems was analyzed in this interaction. A secreted protein belonging to a class of lectins called the ricin B-like (R-type, $\beta$-trefoil) lectin, another putative MAMP, was down-regulated in this interaction. Thirteen genes belonging to four gene families, including four hydrophobins, three ceratoplatanins, five thaumatin-like proteins and three ferric reductases were down-regulated. Similarly, three GPIanchored domain proteins, that are localized to the cell wall and involved in signaling pathways in cell wall 


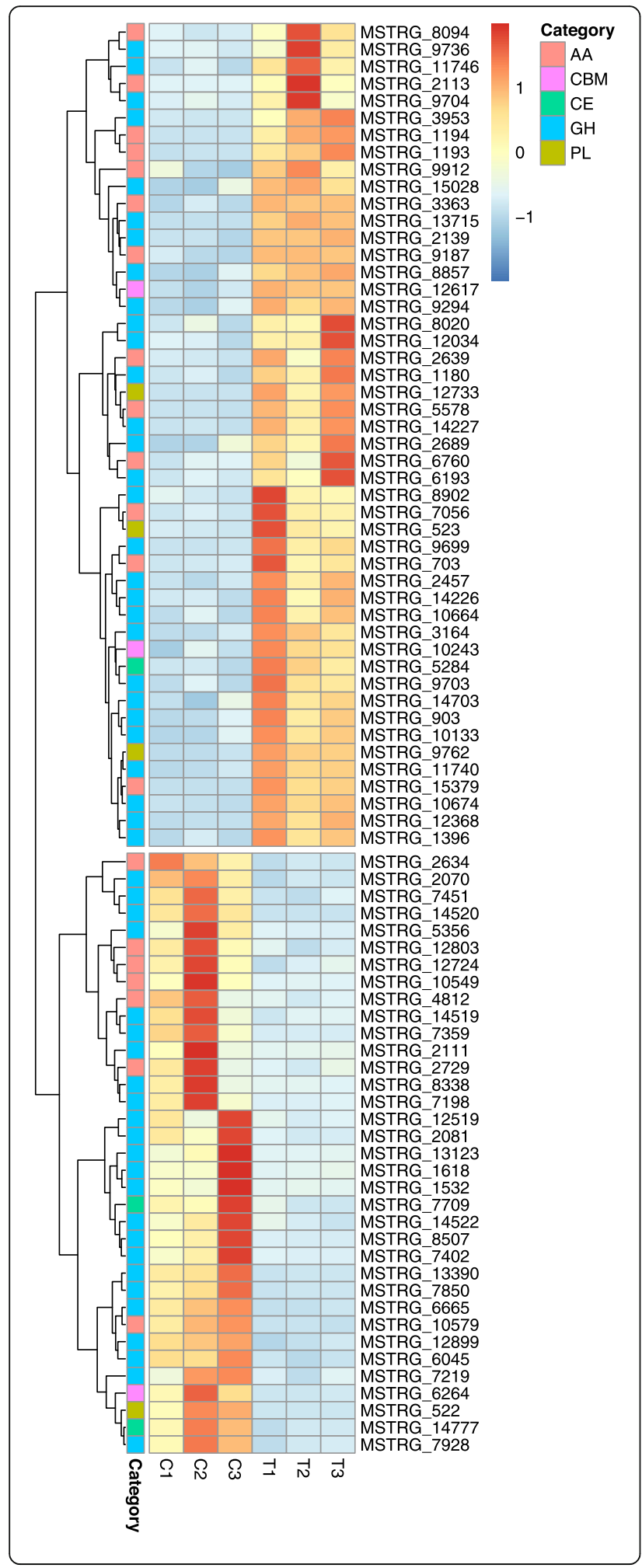

Fig. 3 Heatmap for CAZymes that were differentially expressed in planta. The expression pattern of CAZymes belonging to five families, auxiliary activities (AA), carbohydrate binding modules (CBM), carbohydrate esterases (CE), glycoside hydrolases (GH) and polysaccharide lyases $(\mathrm{PL})$ is shown here. Columns labelled as $C$ and T represent the two growth conditions, i.e., G. boninense growing in vitro on artificial medium, and $G$. boninense interacting with oil palm host (in planta), respectively. Gene expression level, expressed as Z-scores calculated from normalized expression values, for each gene is color coded, with red and blue being up- and downregulated genes, respectively. Rows (genes) were clustered hierarchically

biogenesis and virulence [18-20], were down-regulated in G. boninense-oil palm interaction.

In G. boninense, 25 cytochrome P450 transcripts were up-regulated during interaction with the host. Two copies of carboxylesterase enzymes, that have been classified as pathogenicity related genes in A. mellea [21], were also up-regulated in G. boninense in planta. Moreover, two copies of Hce2 homologs from G. boninense were determined to be up-regulated in planta $\left(\log _{2} \mathrm{FC}=7.76\right.$, $p_{\text {adj }}=2.61 \mathrm{E}-35 ; \log _{2} \mathrm{FC}=6.03$, $\mathrm{p}_{\text {adj }}=1.03 \mathrm{E}-19$ ).

\section{Secreted and lineage-specific proteins}

A total of 89 (22.1\%) of the predicted secreted proteins have an altered expression pattern when G. boninense interacts with palm tissue (Fig. 4), including 38 proteins up-regulated in planta. Six secreted proteins were identified as lineage-specific based on lack of similarity to proteins in the NCBI nr database and no known Pfam domains. Three of the secreted lineage-specific proteins were in the top-20 most up-regulated genes during the interaction. One of the most highly up-regulated genes $\left(\log _{2} \mathrm{FC}=12.03, \quad \mathrm{p}_{\mathrm{adj}}=1.37 \mathrm{E}-71\right)$ is a secreted protein that carries the CFEM domain, which is unique to fungi [22]. Among the up-regulated secreted proteins four were identified as hypothetical proteins and eight proteins had domains characteristic of CAZymes.

\section{Peptidases, transporters and other genes}

Peptidases are involved in various activities ranging from housekeeping to plant-pathogen interaction. Four S10 (carboxypeptidase Y) including one secreted S10, and three other serine peptidases, S8 (subtilisin), S24 (LexA repressor), and S53 (sedolisin), were up-regulated in planta. Eleven aspartyl peptidases (APs) including two secreted APs, and five metalloproteases including two M48 (STE24), one each of M1 (membrane alanyl aminopeptidase), M20 (glutamate carboxypeptidase), and M24 (methionyl aminopeptidase 1), were up-regulated in G. boninense during the interaction. Two protease families, S8 and M1, are two of the most common peptidase families found in fungi [23]. Additionally, one amino acid 


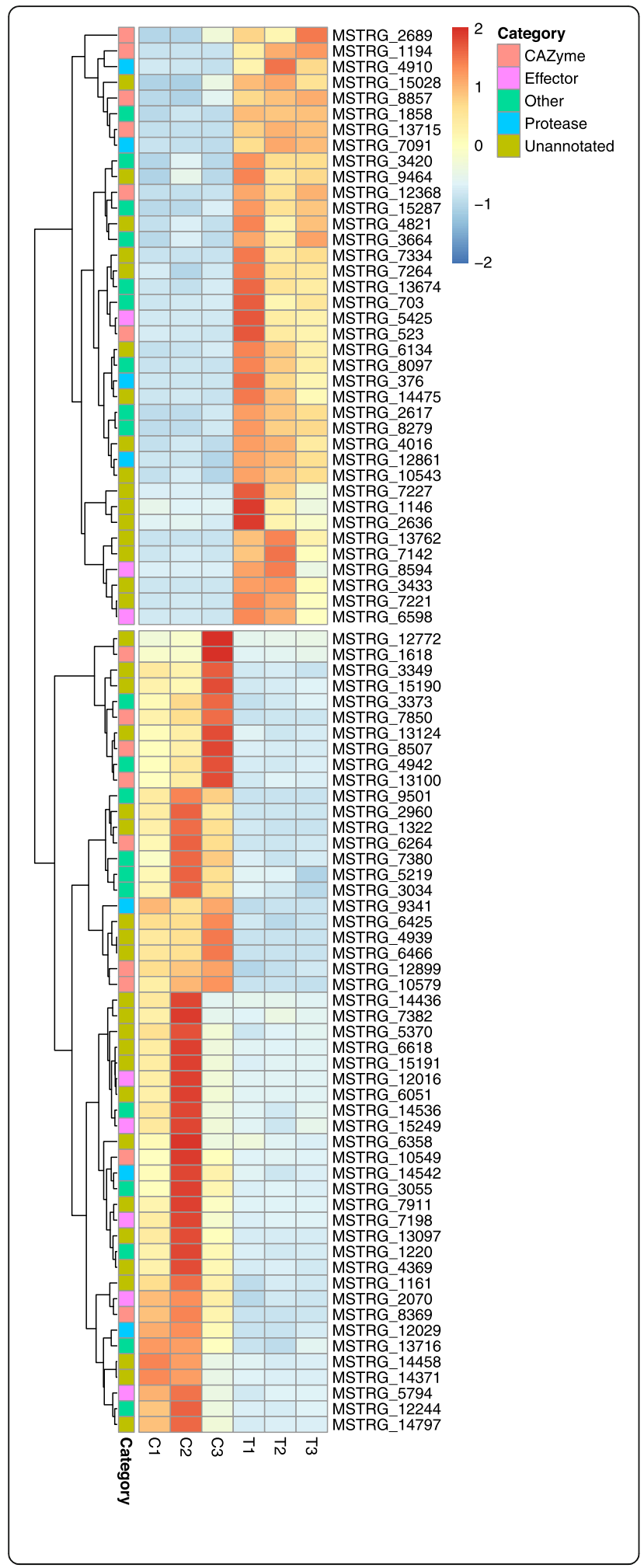

Fig. 4 Heatmap for secreted proteins that were differentially expressed in planta. Differentially expressed secreted proteins were grouped in to five categories, CAZymes, effectors, proteases, others and unannotated. Columns labelled as $C$ and $T$ represent the two growth conditions, i.e., $\mathrm{G}$. boninense growing in vitro on artificial medium, and $G$. boninense interacting with oil palm host (in planta), respectively. Gene expression level, expressed as Z-scores calculated from normalized expression values, for each gene is color coded, with red and blue being up- and down-regulated genes, respectively. Rows (genes) were clustered hierarchically

permease and two oligopeptide transporters were upregulated during the interaction.

Major facilitator superfamily (MFS1) has been associated with pathogenicity and other metabolic roles in fungi [21]. Seventeen MFS transporters with different Pfam domains, including six MFS1, four MFS_FEN2_like copies, one MFS_FucP_MFSD4_like, and one MFS_ MFSD8 were up-regulated during interaction in G. boninense, whereas, only three $\mathrm{ABC}$ transporters were found to be up-regulated in planta.

Among other hydrolases, four copies of lipid metabolizing enzymes or lipases and enzymes involved in benzenering metabolism, i.e. haloacid dehalogenases (HAD; five copies) were up-regulated in planta. Both these classes of enzymes were up-regulated during woody tissue colonization in the white-rot fungus, P. chrysosporium [24].

\section{Cellular respiration and carbon catabolite repression}

All 33 copies of the enzymes that are key in oxidative phosphorylation steps of respiration, including cytochrome b, cytochrome c, and cytochrome-related assembly proteins were down-regulated in G. boninense during infection. Transcripts for other enzymes, such as ATP synthases (seven copies) and those carrying the CoA binding domain were down-regulated as well. The alternative oxidase (AOX), a part of the electron transport chain was also down-regulated during the interaction. The proton antiporters (six copies) that are the proton conducting membrane transporters were also downregulated. Moreover, transcripts of genes in the mitochondrial protein import system that are involved in mitochondrial biogenesis, mitochondrial carrier proteins, and mitochondrial translation activator, MAM33, were all down-regulated during the interaction as well.

The lack of abundant glucose would derepress cell wall degrading enzymes in a process known as carbon catabolite repression $[25,26]$. Consistent with this regulation, a majority (80\%) of the G. boninense glycosyl hydrolases that target plant cell wall components were downregulated during growth on artificial medium.

\section{Discussion}

Our analyses of G. boninense transcriptome as it colonizes its oil palm host revealed that genes in multiple 
biochemical pathways were differentially expressed early during the interaction, primarily those involved in breakdown and assimilation of metabolites and complex polysaccharides of plant origin, fungal biomass accumulation, generation of microbe-associated molecular patterns (MAMPs) and extracellular lineage-specific proteins, and cellular respiration.

Several transcripts with a role in pathogenesis such as, cerato-platanins, thaumatin-like proteins, ricin B-like lectin, hydrophobins, and ferric reductases were downregulated in this interaction. Contrary to what was observed in G. boninense - oil palm interaction, proteins from three gene families, hydrophobins, cerato-platanins and fungal pathogenesis-related CAP protein, were upregulated during the basidiomycete pathogen Moniliophthora roreri interaction with its host, cacao [27]. Host plants can sense cerato-platanin that is either extracellular or present in the fungal cell wall and mount a defense response [28]. Down-regulation of these MAMPs, that have the potential to trigger a host immune response, lends support to the hypothesis that while maintaining stealth growth, G. boninense can stay undetected and evade recognition by the host.

Besides their role in pathogenicity, these proteins play roles in diverse molecular processes. In fact, three classes of secreted proteins, i.e., cerato-platanin, thaumatin and ricin B-like lectin, were reported to be developmentally regulated in basidiomycetes during fruiting body formation [29]. Proteins with cerato-platanin domain were involved in host-pathogen interactions, but these are not necessarily virulence factors [28]. The carbohydrate binding ricin B-like lectins isolated from mushrooms have been studied as nematotoxins or entomotoxins [30] but their role in plant pathogen interaction has not yet been elucidated.

Similarly, other pathogenicity related proteins, such as, CFEM, Hce2, cytochrome P450s and carboxylesterases, that were up-regulated at the sampled infection timepoint also play a role in other diverse processes in fungi. Homologs of C. fulvum Ecp2 (Hce2) are putative effectors found in multiple fungal species that have possible roles in stress response and adaptation to new ecological niches [31]. Besides its role in lignocellulose degradation, the cytochrome P450 gene family has also been catalogued with pathogenicity related function in Armillaria mellea [21]. CFEM domain proteins are involved in a number of different activities, from host-pathogen interaction in Magnaporthe oryzae [32, 33] and Candida albicans [34] to cell wall biogenesis in Saccharomyces cerevisiae $[35,36]$.

During normal growth, chitin biosynthesis genes like chitin synthases (CHS) and endochitinases [37] are needed for hyphal development and maintenance of cell wall integrity in fungi [38]. The observed up-regulation of CHS and endochitinases suggests that the fungus is growing and increasing in biomass during the interaction. On the other hand, products of chitin breakdown, chitin oligosaccharides, can be recognized by the plant LysM motif containing receptor proteins and elicit immune response [39]. Fungal LysM proteins sequester chitin oligosaccharides thereby preventing detection by the host immune system, as demonstrated for LysM effector Ecp6 from the tomato pathogen, Fulvia fulva [40]. The LysM domains in fungi may also interact with chitin from other fungal mycoparasites [41]. Besides chitin, LysM domains may also bind another related molecule, peptidoglycan, that is extensively present in bacterial cell walls [42]. Therefore, the four down-regulated LysM proteins might function in ecological niches where $G$. boninense has to contend with other fungal or bacterial competitors, like those encountered in the soil.

The RNAseq data acquired in this single time-point pilot study provides a snapshot of the differentially expressed transcripts during G. boninense-oil palm interaction. In artificial inoculation studies, Ganoderma colonized rubberwood blocks are introduced in the palm rhizosphere to initiate root infection. The length of time it takes for G. boninense to colonize and kill the host depends on a number of factors, including, the amount of inoculum, proximity of inoculum to the roots, the soil temperature and plant age [10]. Even though younger palms can survive for 6-24 months after infection, foliar symptoms are visible at 2 months post inoculation [10]. This suggests that the process of host colonization initiated by $G$. boninense would be fairly advanced at 4 weeks after inoculation, the time point when samples were collected in the study analyzed here.

A wide range of conditions have been used to understand the transcriptomic response of Ganoderma species to different treatments but only one dataset [14] i.e. the one analyzed in this study, had replicated measures of the transcriptional changes that occur during G. boninensepalm interaction. Early time points of 3-, 7- and 11-days post inoculation were used to understand the host response in G. boninense-oil palm interaction (NCBI BioProject PRJEB27915; [43]). However, wood decay fungi act slowly, and it is likely that early sampling of the interaction might not reveal much about the transcriptional changes occurring during host colonization. RNAseq datasets that comprise of a single time-point at 4 weeks are more likely to reveal components of the host colonization process than multiple early time-points. For white-rot fungi like Moniliophthora perniciosa, responsible for witches' broom on cacao, a longer time frame of 30 days was used for RNAseq to document the transcriptional responses during host colonization [44]. Two additional datasets, one from roots (NCBI BioProject PRJEB7252 [45];) and the other from leaves (NCBI BioProject 
PRJEB17971 [46];) also document the G. boninense-palm interaction, but all replicates per treatment were pooled before sequencing. Thus, the dataset analyzed here appears optimal for capturing the genes and processes important for G. boninense colonization of its palm host.

The presence of simple sugars can suppress the expression of fungal genes involved in breakdown and uptake of complex sugars in a process known as carbon catabolite repression (CCR). Addition of glucose decreased the secretion of lignocellulolytic enzymes in Pleurotus ostreatus [25]. The existence of CCR was also demonstrated in a white-rot fungus, Dichomitus squalens [26], a species closely related to Ganoderma. Analysis of the transcriptome and proteome data showed that presence of glucose repressed the expression of $\sim 7 \%$ genes, primarily CAZymes and carbon catabolic genes, in $D$. squalens [26]. In the current DEGs dataset, $28(80 \%)$ of the in planta expressed glycosyl hydrolases, that target cellulose and hemicellulose components of plant cell wall, were down-regulated when $G$. boninense was grown on artificial media, a relatively simple carbon source as compared to palm roots. Understanding the CCR mechanism in white-rot fungi would facilitate the development of modified strains with improved CAZyme transcription profile needed for biofuel production.

White-rot fungi preferentially remove lignin [47] leaving cellulose as the primary constituent of cells in delignified plant cell walls [48]. Removal of lignin provides easy access to cellulose and hemicellulose that are processed into oligo- and monosaccharides [49]. Thus, breakdown of plant cell wall requires concerted effort from different enzyme families specializing in targeting specific components [49]. A number of G. boninense carbohydrate active enzymes (CAZymes) were upregulated during colonization of palm lignocellulosic substrate. Certain CAZymes, like, GH3, GH28, LPMO (AA9, formerly GH61), PODs (class II peroxidases) and MCOs (multi copper oxidases) that have expanded in white-rot fungi [50] were up-regulated in planta in this interaction. The CAZymes up-regulated early in the infection process in another white-rot fungus, Heterobasidion irregulare, such as, pectin degrading enzymes (polysaccharide lyases and GH28) cell wall targeting enzymes (GH1, GH61) and enzymes with CBM1 modules [51], were also found to be up-regulated in G. boninense. In fungi, especially phytopathogens, the CAZyme profiles may be tailored to the cell wall composition of their respective monocot or dicot hosts [52]. The enzyme profile of $G$. boninense during growth on different carbon sources would help determine if it has the capacity to colonize substrates beyond those typically associated with monocots.

Auxiliary enzymes are essential for facilitating the cell wall degradation process even though these cannot breakdown lignocellulosic compounds. One large gene family with auxiliary function in lignin modification is the Cytochrome P450s that detoxify the aromatic byproducts resulting from lignin breakdown [53]. Another auxiliary biochemical process facilitating lignin degradation is the halogenation and dehalogenation of aromatic rings. Chloroperoxidases were shown to chlorinate (halogenate) and cleave lignin components [54]. The halogenated aromatic rings may then become substrates for haloacid dehalogenase (HAD) enzymes that split carbon-halogen bonds and play an auxiliary role in lignin depolymerization. The in planta concerted expression of CAZymes, auxiliary enzymes like Cytochrome P450s and HADs, other genes involved in oxalic acid degradation and transporter proteins involved in shuttling toxic by-products and maintaining cellular homeostasis, suggests that $G$. boninense was actively involved in cellular decay when the plant tissue was sampled onemonth post inoculation.

Oxalic acid plays a role in pathogenesis in necrotrophic fungi [55] as well as promoting degradation of wood lignin in white-rot fungi [56]. But as oxalic acid is toxic, specific genes like oxalate decarboxylases (ODCs) belonging to the bicupin family and oxalate oxidases are needed for its degradation [56]. Another class of genes, formate dehydrogenases (FDHs), that breakdown the formate generated by the ODC genes [56] were also upregulated. The up-regulation of oxalate breakdown genes coupled with lack of oxalate biosynthesis gene expression in G. boninense suggests that it could also be a response to counteract oxalate production by the host.

This study provides a glimpse into the transcriptional changes that occur in G. boninense as it interacts with oil palm roots. Another Ganoderma species described on palms that is relevant in North American landscapes, $G$. zonatum, groups with its sister species, G. boninense, in clade $C$ [6]. It remains to be seen whether convergent or divergent evolution played a role in the origin of host preference for palms in these two lineages of Ganoderma.

\section{Conclusions}

This analysis identified Ganoderma boninense genes that facilitate the colonization of roots of its oil palm host, Elaeis guineensis. The expression of a number of CAZymes involved in plant cell wall degradation and other auxiliary enzymes, such cytochrome P450s and HAD proteins, that function to breakdown byproducts of degradation were up-regulated during the interaction. Several G. boninense pathogenicity-related genes and those responsible for oxidative phosphorylation and mitochondrial biogenesis were identified as down-regulated in planta. In conclusion, this examination of G. boninenseoil palm interaction offers a prelude to understanding how white-rot fungi in the genus Ganoderma colonize palms. 


\section{Methods}

\section{Data retrieval}

Genome sequence for Ganoderma boninense isolate G3, collected from North Sumatra province in Indonesia, was downloaded from NCBI (BioProject PRJNA421251; [13]). The interaction of G. boninense isolate PER71 with oil palm, Elaeis guineensis, was sampled at a single time point, one-month post inoculation [14]. Briefly, the experiment was comprised of two growth conditions: 1) in vitro - G. boninense culture grown on artificial media with three replicates (SRA samples, SRR8432491SRR8432493), and 2) in planta - E. guineensis roots inoculated with $G$. boninense colonized rubberwood blocks in three replicates (SRA samples, SRR8432494SRR8432496). RNA was isolated from fungal cultures and roots of five-month infected oil palm seedlings and sequenced on the Illumina HiSeq 1000 platform. The data for these six samples was downloaded from NCBI (BioProject PRJNA514399; [14]).

\section{RNAseq analysis}

A data analysis pipeline was built to identify and characterize the RNAseq dataset (Fig. 5). The reads for the six samples downloaded from NCBI were mapped to the unmasked $G$. boninense genome using the spliceaware aligner HISAT2 ver.2.1.0 [57]. The resulting mapping files (SAM format) for each sample were converted to compressed BAM format and sorted using SAMtools ver.1.9 [58] before doing transcript assembly with StringTie ver.2.0.6 [59] (Additional file 2: Dataset S1) and estimating raw counts for transcript abundance. The raw counts matrix was formatted using 'prepDE.py', a python script provided with StringTie, and used as input for differential gene expression analysis with $\mathrm{R}$ v.3.6.3 package DESeq2 [60]. For each transcript locus, normalized read counts along with fold change and false discovery rate (FDR)-adjusted $p$-values ( $\mathrm{p}_{\mathrm{adj}}$ ) were obtained from DESeq2. Three criteria were used to define a set of differentially expressed genes (DEGs), i) absolute value $\left[\log _{2} \mathrm{FC}\right.$ (fold change) $>2$ ], ii) $p$-value adjusted for multiple testing, $\mathrm{p}_{\mathrm{adj}}<0.05$, and iii) non-zero normalized count values across all treatments. Heatmaps for DEGs were generated using $\mathrm{R}$ v.3.6.3 package pheatmap v.1.0.12 [61].

\section{Annotation}

The StringTie assembled transcript sequences (Additional file 3: Dataset S2) were annotated using the Reverse Position-Specific BLAST (RPS-BLAST) tool [15] from NCBI. RPS-BLAST utilizes a database of precomputed Position-Specific Score Matrix (PSSM) to identify protein domains in either nucleotide or protein query sequences. A standalone version of RPS-BLAST, also known as CD-Search (Conserved Domain Search), along with 'rpsbproc' a command line utility to process RPS-BLAST results, were downloaded from NCBI FTP ftp://ftp.ncbi.nlm.nih.gov/pub/mmdb/cdd/. Two preformatted protein domain databases, NCBI Conserved Domain Database (CDD [62];) and Pfam [63], containing PSSMs were accessed from the above FTP service and used to search the StringTie derived transcript dataset. Protein domain name and descriptions were transferred to the transcripts based on the CD-Search results. Additionally, ENTAP (Eukaryotic Non-Model Transcriptome Annotation Pipeline [64];) was used to annotate the complete set of assembled transcripts. The ENTAP pipeline utilized DIAMOND [65] for protein alignment and three databases, NCBI nr (v4), Uniprot (release-2020_01) and fungal sequences from NCBI RefSeq (RefSeq-

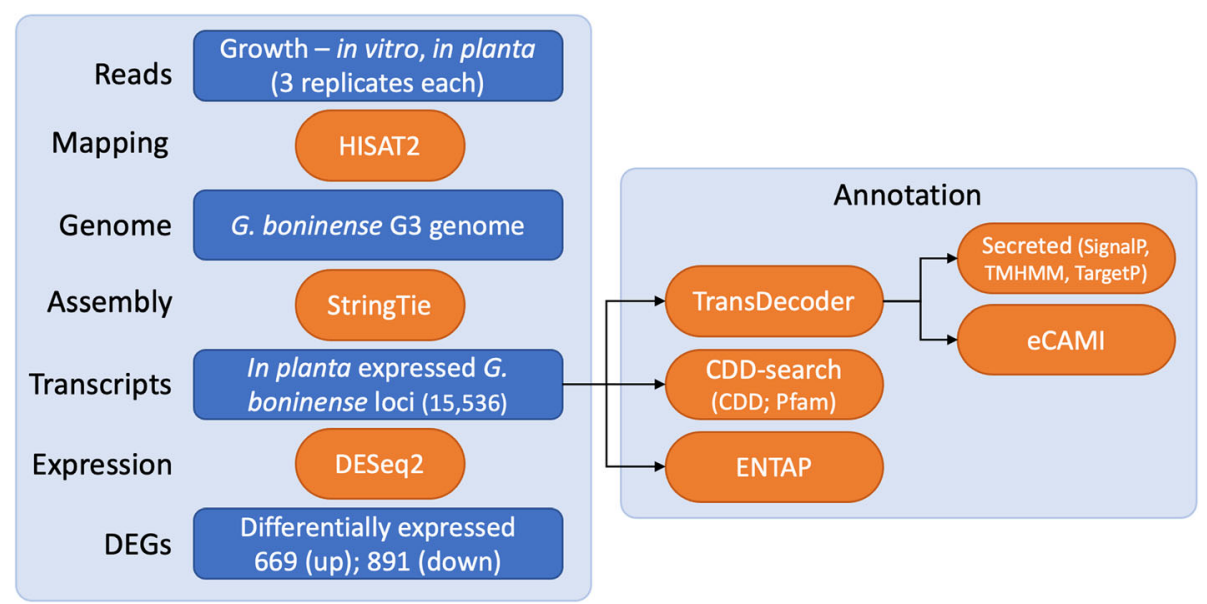

Fig. 5 Identification and annotation of transcripts and differentially expressed genes (DEGs). A schematic for the pipeline used to generate transcript loci and identify differentially expressed genes (DEGs). The assembled transcripts were annotated both at the nucleotide and protein level 
release200.txt) were used to annotate proteins. The CDSearch and ENTAP output for the DEGs was compared manually. A discrepancy in the output from the two pipelines, if any, was resolved by comparing to NCBI BLAST search results. The results for a small percentage ( 2\%) of DEGs were also manually curated using NCBI BLAST.

The assembled transcripts were translated to proteins using TransDecoder-ver.5.5.0 [66]. Two flags, a minimum protein length of 50 amino acids $(-\mathrm{m} 50)$ and '--single_best_only' were used. The resulting protein dataset was parsed to retain proteins that started with a Methionine at the N-terminus (Additional file 4: Dataset S3). A simple custom pipeline was used to predict secreted proteins from the parsed protein dataset. Briefly, proteins with a signal peptide (signalP-5.0b; [67]) that lacked a transmembrane helix (tmhmm-2.0c; [68]) and targeted to secretory pathway (targetP-2.0; [69]) were considered as secreted proteins. Carbohydrate active enzymes (CAZymes) were predicted by using a k-mer based tool called eCAMI (simultaneous enzyme Classification And Motif Identification; [70]) that compared the parsed protein dataset against the CAZy database [71]

\section{Abbreviations}

Nr: Non-redundant database; NCBI: National Center for Biotechnology Information; CDD: Conserved domain database; Pfam: Protein family; GDP: Gross domestic product; CCR: Carbon catabolite repression; DEGs: Differentially expressed genes; CAZYmes: Carbohydrate-Active enZYmes; GH: Glycoside hydrolase; GT: Glycosyl transferase; CBM: Carbohydrate binding module; PL: Polysaccharide lyase; CE: Carbohydrate esterase; ABC: ATP binding cassette; HAD: Haloacid dehalogenase; ODC: Oxalate decarboxylase; FDH: Formate dehydrogenase; LPMO: Lytic polysaccharide monooxygenase; POD: Peroxidase; MCO: Multi copper oxidase; CHS: Chitin synthase; Hce2: Homologs of C. fulvum Ecp2; CFEM: Common in several fungal extracellular membrane protein; CAP: Cysteine-rich secretory proteins, antigen 5, and pathogenesis-related 1 proteins; AOX: Alternative oxidase; MFS: Major facilitator superfamily; CoA: Coenzyme A; ATP: Adenosine triphosphate; MAM33: Mitochondrial acidic matrix protein; MAMP: Microbe-associated molecular pattern; PX: Phox domain

\section{Supplementary Information}

The online version contains supplementary material available at https:/doi. org/10.1186/s12864-021-07644-9.

\section{Additional file 1: Table S1. The expression, annotation and} coordinates of $G$. boninense transcripts. Normalized expression values, log2 fold-change and p-adj values for 15,536 transcript loci are listed in this table. Protein domain names and descriptions obtained from two databases, CDD and Pfam, and results from three pipelines, ENTAP, secreted protein and eCAMI (CAZymes) are presented for the 1560 differentially expressed genes. Value 'YES' in ENTAP column means that the annotation was manually curated (last column). The values with an asterisk in the CAZyme column were results obtained from other annotation sources. CDD and Pfam domain names, and results from CAZyme and secretion signal detection pipeline are included for the remaining transcript loci.

Additional file 2: Dataset S1. StringTie transcript gtf annotation.

Additional file 3: Dataset S2. StringTie assembled transcripts.

Additional file 4: Dataset S3. TransDecoder derived proteins.

\section{Acknowledgements}

This work is supported by the USDA National Institute of Food and Agriculture, Hatch project FLA-FTL-005926. Any opinions, findings, conclusions, or recommendations expressed in this publication are those of the author(s) and do not necessarily reflect the view of the National Institute of Food and Agriculture (NIFA) or the United States Department of Agriculture (USDA). The original research summarized in the following was supported, in part, by U.S. Department of Education grant award P031C160143 (STEM EnglnE). Any opinions, findings, and conclusions or recommendations expressed in this material are those of the authors and do not necessarily reflect the views of the funding agency. The authors would like to thank Dr. Monica L. Elliott, Professor Emeritus, University of Florida, for her critical review and suggestions to improve the manuscript. The authors are grateful to Wong Lab at Universiti Putra Malaysia and PT SMART Tbk, Bogor, Indonesia for the publicly available genomic resources for $G$. boninense that were used in this study.

\section{Authors' contributions}

$\mathrm{BD}$ conceived the study, performed the analysis, and wrote the manuscript. $\mathrm{RCH}$ and JAR helped with drafting the manuscript and critical review. All authors read and approved the final manuscript.

\section{Funding}

This work is supported by the USDA National Institute of Food and Agriculture, Hatch project FLA-FTL-005926 and by the U.S. Department of Education grant award P031C160143 (STEM EnglnE).

\section{Availability of data and materials}

The data generated in this study are included in this manuscript and additional files.

The reference genome assembly used for data analysis was obtained from National Center for Biotechnology Information (NCBI) BioProject

PRJNA421251 and can be accessed from this link, https://www.ncbi.nlm.nih. gov/nuccore/PJEW00000000. The raw transcriptome data used in the analysis can be obtained from NCBI BioProject PRJNA514399, and can be downloaded from the following links:

https://sra-downloadb.be-md.ncbi.nlm.nih.gov/sos1/sra-pub-run-2/SRR84324 91/SRR8432491.1

https://sra-downloadb.be-md.ncbi.nlm.nih.gov/sos1/sra-pub-run-2/SRR84324 92/SRR8432492.1

https://sra-downloadb.be-md.ncbi.nlm.nih.gov/sos1/sra-pub-run-2/SRR84324 93/SRR8432493.1

https://sra-downloadb.be-md.ncbi.nlm.nih.gov/sos1/sra-pub-run-2/SRR84324 94/SRR8432494.1

https://sra-downloadb.be-md.ncbi.nlm.nih.gov/sos1/sra-pub-run-2/SRR84324 95/SRR8432495.1

https://sra-downloadb.be-md.ncbi.nlm.nih.gov/sos1/sra-pub-run-2/SRR84324 96/SRR8432496.1

\section{Declarations}

Ethics approval and consent to participate

Not applicable.

\section{Consent for publication}

Not applicable.

\section{Competing interests}

The authors declare no competing interests.

\section{Author details}

'Department of Plant Pathology, University of Florida, Fort Lauderdale Research and Education Center, Davie, FL 33314, USA. ${ }^{2}$ Department of Forest and Conservation Sciences, Faculty of Forestry, University of British Columbia, Vancouver, BC, Canada. ${ }^{3}$ Department of Plant Pathology, University of Florida, 1453 Fifield Hall, Gainesville, FL 32611-0680, USA. 


\section{Received: 23 September 2020 Accepted: 23 April 2021}

\section{Published online: 05 May 2021}

\section{References}

1. Riley R, Salamov AA, Brown DW, Nagy LG, Floudas D, Held BW, et al. Extensive sampling of basidiomycete genomes demonstrates inadequacy of the white-rot/brown-rot paradigm for wood decay fungi. Proc Natl Acad Sci U S A. 2014;111(27):9923-8. https://doi.org/10.1073/pnas.1400592111.

2. Martinez D, Challacombe J, Morgenstern I, Hibbett D, Schmoll M, Kubicek $\mathrm{CP}$, et al. Genome, transcriptome, and secretome analysis of wood decay fungus Postia placenta supports unique mechanisms of lignocellulose conversion. Proc Natl Acad Sci U S A. 2009;106(6):1954-9. https://doi.org/1 0.1073/pnas.0809575106

3. Murrill WA. The Polyporaceae of North America. I The Genus Ganoderma. Bull Torrey Bot Club. 1902;29(10):599. https://doi.org/10.2307/2478682.

4. Nobles MK. Studies in forest pathology; identification of cultures of wood-rotting fungi. Can J Res. 1948;26(3):281-431. https://doi.org/10.113 9/cjr48c-026.

5. Gilbertson RL, Ryvarden L. North American Polypores. Vol. 1 (Abortiporus-Lindtneria). 433 S. 209 Abb. Fungiflora. Oslo, 1986. Feddes Repert. 1987;98:136

6. Loyd AL, Barnes CW, Held BW, Schink MJ, Smith ME, Smith JA, et al. Elucidating "lucidum": distinguishing the diverse laccate Ganoderma species of the United States. PLoS One. 2018;13(7):e0199738. https://doi.org/10.13 71/journal.pone.0199738.

7. Zhou LW, Cao Y, Wu SH, Vlasák J, Li DW, Li MJ, et al. Global diversity of the Ganoderma lucidum complex (Ganodermataceae, Polyporales) inferred from morphology and multilocus phylogeny. Phytochemistry. 2015;114:7-15. https://doi.org/10.1016/j.phytochem.2014.09.023.

8. USDA. USDA FAS World Agricultural Production. 2018. https://www.fas.usda. gov/data. (Accessed on 31 Jan 2019).

9. Europe, Economics. The downstream economic impacts of palm oil exports. 2016. http://theoilpalm.org/wp-content/uploads/2016/09/Palm-OilEconomics-Full-Study-1.pdf.

10. Rees RW, Flood J, Hasan Y, Cooper RM. Effects of inoculum potential, shading and soil temperature on root infection of oil palm seedlings by the basal stem rot pathogen Ganoderma boninense. Plant Pathol. 2007:56(5): 862-70. https://doi.org/10.1111/j.1365-3059.2007.01621.x.

11. Midot F, Lau SYL, Wong WC, Tung HJ, Yap ML, Lo ML, et al. Genetic diversity and demographic history of Ganoderma boninense in oil palm plantations of Sarawak, Malaysia inferred from ITS regions. Microorganisms. 2019;7:464.

12. Elliott ML, Des Jardin EA, Ortiz JV, Macias T. Genetic variability of Ganoderma zonatum infecting palms in Florida. Mycologia. 2018;110(2):339-46. https:// doi.org/10.1080/00275514.2018.1442083.

13. Utomo C, Tanjung ZA, Aditama R, Buana RFN, Pratomo ADM, Tryono R, et al. Draft genome sequence of the phytopathogenic fungus Ganoderma boninense, the causal agent of basal stem rot disease on oil palm. Genome Announc. 2018;6:e00122-18.

14. Wong MY, Govender NT, Ong CS. RNA-seq data of Ganoderma boninense at axenic culture condition and under in planta pathogen-oil palm (Elaeis guineensis Jacq.) interaction. BMC Res Notes. 2019;12(1):631. https://doi.org/1 0.1186/s13104-019-4652-y.

15. Marchler-Bauer A, Bryant SH. CD-search: protein domain annotations on the fly. Nucleic Acids Res. 2004;32(Web Server):W327-31. https://doi.org/10.1 093/nar/gkh454

16. Konno N, Takahashi H, Nakajima M, Takeda T, Sakamoto Y. Characterization of $\beta$-N-acetylhexosaminidase (LeHex20A), a member of glycoside hydrolase family 20, from Lentinula edodes (shiitake mushroom). AMB Express. 2012; 2(1):29. https://doi.org/10.1186/2191-0855-2-29.

17. Karlsson M, Stenlid J, Lindahl B. Functional differentiation of chitinases in the white-rot fungus Phanerochaete chrysosporium. Fungal Ecol. 2016;22:5260. https://doi.org/10.1016/j.funeco.2016.04.004.

18. Romano J, Nimrod G, Ben-Tal N, Shadkchan Y, Baruch K, Sharon H, et al. Disruption of the Aspergillus fumigatus ECM33 homologue results in rapid conidial germination, antifungal resistance and hypervirulence. Microbiology. 2006;152(7):1919-28. https://doi.org/10.1099/mic.0.28936-0.

19. Plaine A, Walker L, Da Costa G, Mora-Montes HM, McKinnon A, Gow NAR, et al. Functional analysis of Candida albicans GPI-anchored proteins: roles in cell wall integrity and caspofungin sensitivity. Fungal Genet Biol. 2008; 45(10):1404-14. https://doi.org/10.1016/j.fgb.2008.08.003.
20. Kuroki M, Okauchi K, Yoshida S, Ohno Y, Murata S, Nakajima Y, et al. Chitindeacetylase activity induces appressorium differentiation in the rice blast fungus Magnaporthe oryzae. Sci Rep. 2017;7(1):9697. https://doi.org/10.1038/ s41598-017-10322-0.

21. Sipos G, Prasanna AN, Walter MC, O'Connor E, Bálint B, Krizsán K, et al. Genome expansion and lineage-specific genetic innovations in the forest pathogenic fungi Armillaria. Nat Ecol Evol. 2017;1(12):1931-41. https://doi. org/10.1038/s41559-017-0347-8.

22. Zhang ZN, Wu QY, Zhang GZ, Zhu YY, Murphy RW, Liu Z, et al. Systematic analyses reveal uniqueness and origin of the CFEM domain in fungi. Sci Rep. 2015;5(1):13032. https://doi.org/10.1038/srep13032.

23. Rawlings ND, Bateman A. Origins of peptidases. Biochimie. 2019;166:4-18. https://doi.org/10.1016/j.biochi.2019.07.026.

24. Skyba O, Cullen D, Douglas CJ, Mansfield SD. Gene expression patterns of wood decay fungi Postia placenta and Phanerochaete chrysosporium are influenced by wood substrate composition during degradation. Appl Environ Microbiol. 2016;82(14):4387-400. https://doi.org/10.1128/AEM. 00134-16.

25. Alfaro M, Majcherczyk A, Kües U, Ramírez L, Pisabarro AG. Glucose counteracts wood-dependent induction of lignocellulolytic enzyme secretion in monokaryon and dikaryon submerged cultures of the white-rot basidiomycete Pleurotus ostreatus. Sci Rep. 2020;10(1):12421. https://doi. org/10.1038/s41598-020-68969-1.

26. Daly P, Peng M, Di Falco M, Lipzen A, Wang M, Ng V, et al. Glucosemediated repression of plant biomass utilization in the white-rot fungus Dichomitus squalens. Appl Environ Microbiol. 2019;85:e01828-19.

27. Meinhardt LW, Costa GGL, Thomazella DPT, Teixeira PJPL, Carazzolle MF, Schuster SC, et al. Genome and secretome analysis of the hemibiotrophic fungal pathogen, Moniliophthora roreri, which causes frosty pod rot disease of cacao: mechanisms of the biotrophic and necrotrophic phases. BMC Genomics. 2014;15(1):164. https://doi.org/10.1186/1471-2164-15-164.

28. Baccelli I. Cerato-platanin family proteins: one function for multiple biological roles? Front Plant Sci. 2015;5:769.

29. Krizsán K, Almási É, Merényi Z, Sahu N, Virágh M, Kószó T, et al. Transcriptomic atlas of mushroom development reveals conserved genes behind complex multicellularity in fungi. Proc Natl Acad Sci U S A. 2019; 116(15):7409-18. https://doi.org/10.1073/pnas.1817822116.

30. Žurga S, Pohleven J, Renko M, Bleuler-Martinez S, Sosnowski P, Turk D, et al. A novel $\beta$-trefoil lectin from the parasol mushroom (Macrolepiota procera) is nematotoxic. FEBS J. 2014;281(15):3489-506. https://doi.org/10.1111/febs.12875.

31. Stergiopoulos I, Van Den Burg HA, Ökmen B, Beenen HG, Van Liere S, Kema $\mathrm{GHJ}$, et al. Tomato Cf resistance proteins mediate recognition of cognate homologous effectors from fungi pathogenic on dicots and monocots. Proc Natl Acad Sci U S A. 2010;107(16):7610-5. https://doi.org/10.1073/pnas.1002 910107.

32. DeZwaan TM, Carroll AM, Valent B, Sweigard JA. Magnaporthe grisea Pth11p is a novel plasma membrane protein that mediates appressorium differentiation in response to inductive substrate cues. Plant Cell. 1999; 11(10):2013-30. https://doi.org/10.1105/tpc.11.10.2013.

33. Kulkarni RD, Kelkar HS, Dean RA. An eight-cysteine-containing CFEM domain unique to a group of fungal membrane proteins. Trends Biochem Sci. 2003; 28:P118-21.

34. Lamarre $C$, Deslauriers $N$, Bourbonnais $Y$. Expression cloning of the Candida albicans CSA1 gene encoding a mycelial surface antigen by sorting of Saccharomyces cerevisiae transformants with monoclonal antibody-coated magnetic beads. Mol Microbiol. 2000;35(2):444-53. https://doi.org/10.1046/ j.1365-2958.2000.01715.x

35. Moukadiri I, Armero J, Abad A, Sentandreu R, Zueco J. Identification of a mannoprotein present in the inner layer of the cell wall of Saccharomyces cerevisiae. J Bacteriol. 1997;179(7):2154-62. https://doi.org/10.1128/JB.179. 7.2154-2162.1997.

36. Mrsa V, Ecker M, Strahl-Bolsinger S, Nimtz M, Lehle L, Tanner W. Deletion of new covalently linked cell wall glycoproteins alters the electrophoretic mobility of phosphorylated wall components of Saccharomyces cerevisiae. J Bacteriol. 1999;181(10):3076-86. https://doi.org/10.1128/JB.181.10.3076-3 086.1999 .

37. Zhou J, Kang L, Liu C, Niu X, Wang X, Liu H, et al. Chitinases play a key role in stipe cell wall extension in the mushroom Coprinopsis cinerea. Appl Environ Microbiol. 2019;85:e00532-19.

38. Zhang J, Jiang H, Du Y, Keyhani NO, Xia Y, Jin K. Members of chitin synthase family in Metarhizium acridum differentially affect fungal growth, stress 
tolerances, cell wall integrity and virulence. PLoS Pathog. 2019;15(8): e1007964. https://doi.org/10.1371/journal.ppat.1007964.

39. Kaku H, Nishizawa Y, Ishii-Minami N, Akimoto-Tomiyama C, Dohmae N, Takio K, et al. Plant cells recognize chitin fragments for defense signaling through a plasma membrane receptor. Proc Natl Acad Sci U S A. 2006; 103(29):11086-91. https://doi.org/10.1073/pnas.0508882103.

40. De Jonge R, Van Esse HP, Kombrink A, Shinya T, Desaki Y, Bours R, et al. Conserved fungal LysM effector Ecp6 prevents chitin-triggered immunity in plants. Science (80- ). 2010;329:953-5.

41. Kombrink A, Thomma BPHJ. LysM effectors: secreted proteins supporting fungal life. PLoS Pathog. 2013;9:1-4.

42. Buist G, Steen A, Kok J, Kuipers OP. LysM, a widely distributed protein motif for binding to (peptido)glycans. Mol Microbiol. 2008;68(4):838-47. https:// doi.org/10.1111/j.1365-2958.2008.06211.x.

43. Bahari MNA, Sakeh NM, Abdullah SNA, Ramli RR, Kadkhodaei S. Transciptome profiling at early infection of Elaeis guineensis by Ganoderma boninense provides novel insights on fungal transition from biotrophic to necrotrophic phase. BMC Plant Biol. 2018;18(1):377. https://doi.org/10.1186/ s12870-018-1594-9.

44. Teixeira PJPL, De Toledo Thomazella DP, Reis O, Prado PFVD, Rio MCSD, Fiorin $\mathrm{GL}$, et al. High-resolution transcript profiling of the atypical biotrophic interaction between Theobroma cacao and the fungal pathogen Moniliophthora perniciosa. Plant Cell. 2014;26(11):4245-69. https://doi.org/1 0.1105/tpc.114.130807.

45. Ho CL, Tan YC, Yeoh KA, Ghazali AK, Yee WY, Hoh CC. De novo transcriptome analyses of host-fungal interactions in oil palm (Elaeis guineensis Jacq.). BMC Genomics. 2016;17(1):66. https://doi.org/10.1186/s12 864-016-2368-0.

46. Ho CL, Tan YC, Yeoh KA, Lee WK, Ghazali AK, Yee WY, et al. Leaf transcriptome of oil palm (Elaeis guineensis Jacq.) infected by Ganoderma boninense. Trees - Struct Funct. 2019;33:943-50.

47. Hartig R. Die Zersetzungserscheinungen des Holzes der Nadelholzbäume und der Eiche in forstlicher, botanischer und chemischer Richtung. Berlin: Springer-Verlag; 1878. https://doi.org/10.5962/bhl.title.25641.

48. Blanchette RA. Screening wood decayed by white rot fungi for preferential lignin degradation. Appl Environ Microbiol. 1984;48(3):647-53. https://doi. org/10.1128/AEM.48.3.647-653.1984.

49. Rytioja J, Hildén K, Yuzon J, Hatakka A, de Vries RP, Mäkelä MR. Plantpolysaccharide-degrading enzymes from basidiomycetes. Microbiol Mol Biol Rev. 2014;78(4):614-49. https://doi.org/10.1128/MMBR.00035-14.

50. Floudas D, Binder M, Riley R, Barry K, Blanchette RA, Henrissat B, et al. The paleozoic origin of enzymatic lignin decomposition reconstructed from 31 fungal genomes. Science (80- ). 2012;336:1715-9.

51. Olson Å, Aerts A, Asiegbu F, Belbahri L, Bouzid O, Broberg A, et al. Insight into trade-off between wood decay and parasitism from the genome of a fungal forest pathogen. New Phytol. 2012;194(4):1001-13. https://doi.org/1 0.1111/j.1469-8137.2012.04128.x.

52. King BC, Waxman KD, Nenni NV, Walker LP, Bergstrom GC, Gibson DM. Arsenal of plant cell wall degrading enzymes reflects host preference among plant pathogenic fungi. Biotechnol Biofuels. 2011;4(1):4. https://doi org/10.1186/1754-6834-4-4.

53. Hirosue S, Tazaki M, Hiratsuka N, Yanai S, Kabumoto H, Shinkyo R, et al. Insight into functional diversity of cytochrome P450 in the white-rot basidiomycete Phanerochaete chrysosporium: involvement of versatile monooxygenase. Biochem Biophys Res Commun. 2011;407(1):118-23. https://doi.org/10.1016/j.bbrc.2011.02.121.

54. Ortiz-Bermúdez P, Srebotnik E, Hammel KE. Chlorination and cleavage of lignin structures by fungal chloroperoxidases. Appl Environ Microbiol. 2003; 69(8):5015-8. https://doi.org/10.1128/AEM.69.8.5015-5018.2003.

55. Godoy G, Steadman JR, Dickman MB, Dam R. Use of mutants to demonstrate the role of oxalic acid in pathogenicity of Sclerotinia sclerotiorum on Phaseolus vulgaris. Physiol Mol Plant Pathol. 1990;37(3):17991. https://doi.org/10.1016/0885-5765(90)90010-U.

56. Mäkelä MR, Sietiö OM, De Vries RP, Timonen S, Hildén K. Oxalatemetabolising genes of the white-rot fungus Dichomitus squalens are differentially induced on wood and at high proton concentration. PLoS One. 2014;9(2):e87959. https://doi.org/10.1371/journal.pone.0087959.

57. Kim D, Langmead B, Salzberg SL. HISAT: a fast spliced aligner with low memory requirements. Nat Methods. 2015;12(4):357-60. https://doi.org/10.1 038/nmeth.3317.
58. Li H, Handsaker B, Wysoker A, Fennell T, Ruan J, Homer N, et al. The Sequence Alignment/Map format and SAMtools. Bioinformatics. 2009;25(16): 2078-9. https://doi.org/10.1093/bioinformatics/btp352.

59. Pertea M, Kim D, Pertea GM, Leek JT, Salzberg SL. Transcript-level expression analysis of RNA-seq experiments with HISAT, StringTie and Ballgown. Nat Protoc. 2016;11(9):1650-67. https://doi.org/10.1038/nprot.2016.095.

60. Love MI, Huber W, Anders S. Moderated estimation of fold change and dispersion for RNA-seq data with DESeq2. Genome Biol. 2014;15(12):550. https://doi.org/10.1186/s13059-014-0550-8.

61. Kolde R. Pheatmap: Pretty Heatmaps. R package version 1.0.12; 2019.

62. Marchler-Bauer A, Lu S, Anderson JB, Chitsaz F, Derbyshire MK, DeWeeseScott C, et al. CDD: a conserved domain database for the functional annotation of proteins. Nucleic Acids Res. 2011;39(Database):D225-9. https://doi.org/10.1093/nar/gkq1189.

63. El-Gebali S, Mistry J, Bateman A, Eddy SR, Luciani A, Potter SC, et al. The Pfam protein families database in 2019. Nucleic Acids Res. 2019;47(D1): D427-32. https://doi.org/10.1093/nar/gky995.

64. Hart AJ, Ginzburg S, Xu M, Fisher CR, Rahmatpour N, Mitton JB, et al. EnTAP: bringing faster and smarter functional annotation to non-model eukaryotic transcriptomes. Mol Ecol Resour. 2020;20(2):591-604. https://doi.org/1 0.1111/1755-0998.13106.

65. Buchfink B, Xie C, Huson DH. Fast and sensitive protein alignment using DIAMOND. Nat Methods. 2015;12(1):59-60. https://doi.org/10.1038/ nmeth.3176.

66. Haas BJ, Papanicolaou A, Yassour M, Grabherr M, Blood PD, Bowden J, et al. De novo transcript sequence reconstruction from RNA-seq using the trinity platform for reference generation and analysis. Nat Protoc. 2013;8(8):1494512. https://doi.org/10.1038/nprot.2013.084.

67. Armenteros JJA, Tsirigos KD, Sønderby CK, Petersen TN, Winther O, Brunak S, et al. SignalP 5.0 improves signal peptide predictions using deep neural networks. Nat Biotechnol. 2019;37(4):420-3. https://doi.org/10.1038/s41587019-0036-z.

68. Sonnhammer EL, von Heijne G, Krogh A. A hidden Markov model for predicting transmembrane helices in protein sequences. Proc Int Conf Intell Syst Mol Biol. 1998;6:175-82.

69. Armenteros JJA, Salvatore M, Emanuelsson O, Winther O, Von Heijne G, Elofsson $A$, et al. Detecting sequence signals in targeting peptides using deep learning. Life Sci Alliance. 2019;2(5):e201900429. https://doi.org/10.2 6508/Isa.201900429.

70. Xu J, Zhang H, Zheng J, Dovoedo P, Yin Y. ECAMl: simultaneous classification and motif identification for enzyme annotation. Bioinformatics. 2020;36(7):2068-75. https://doi.org/10.1093/bioinformatics/btz908.

71. Lombard V, Golaconda Ramulu H, Drula E, Coutinho PM, Henrissat B. The carbohydrate-active enzymes database (CAZy) in 2013. Nucleic Acids Res, 2014;42(D1):D490-5. https://doi.org/10.1093/nar/gkt1178.

\section{Publisher's Note}

Springer Nature remains neutral with regard to jurisdictional claims in published maps and institutional affiliations.
Ready to submit your research? Choose BMC and benefit from:

- fast, convenient online submission

- thorough peer review by experienced researchers in your field

- rapid publication on acceptance

- support for research data, including large and complex data types

- gold Open Access which fosters wider collaboration and increased citations

- maximum visibility for your research: over $100 \mathrm{M}$ website views per year

At BMC, research is always in progress.

Learn more biomedcentral.com/submissions 